mural and choroidal, depending on the respective feeding vessels. At presentation, VOGM is known to cause additional complications in the neonate including hydrocephalus, congestive heart failure, and seizures. Treatment options include coil and microparticle embolization in addition to the recent introduction of the microvascular plug used traditionally for arterial occlusion. In this case presentation, we present the second known case of use of the microvascular plug (MVP) to assist with venous occlusion for a VOGM

Method/Case presentation A 39 weeks male was born via an urgent Cesarean section for right atrial dilation, cardiac arrhythmia thought to be premature atrial complexes and a cerebral vascular malformation. His mother had had a recent fetal ultrasound demonstrating intrauterine growth restriction. Head ultrasound performed after birth demonstrated a large vein of Galen malformation. MRI with angiography and venography demonstrated a $4.3 \times 3.6 \times 4.1$ centimeter aneurysmal VOGM with primary supply via a dilated right superior cerebellar artery and primary drainage via a dilated median prosencephalic vein.

Intervention/Result Postpartum day 7, the patient showed signs and symptoms of worsening heart failure. Treatment was deemed necessary. The left vertebral artery was catheterized and multiple runs performed revealing a mural type vein of Galen malformation with direct AV fistula from the supplying right superior cerebellar artery. The right superior cerebellar artery was measured at approximately $3.8 \mathrm{~mm}$ in diameter. A 3-5 mm Microvascular Plug device was chosen for primary embolization. Post MVP deployment angiographic runs showed decreased flow through the fistula. Three coils were then deployed followed by Onyx 34 in order to completely obliterate the fistula. Final angiographic runs revealed fistula obliteration and patent basilar artery, posterior cerebral arteries, left superior cerebellar artery and left PICA. Follow up cranial US with smaller ventricular size and repeat echocardiography with stable hemodynamics and without evidence of heart failure.

Conclusion This is the second case documented in the literature demonstrating the utility of the microvascular plug for assistance in embolization of a VOGM. The utility of this device is limited by vessel diameter and appropriate landing zone requirements. Further investigation is needed to assess feasibility as well as short and long term outcomes and possible related complications from embolization including postoperative development of hydrocephalus which common in both our case and the previously published literature.

Disclosures M. Mathkour: None. E. McCormack: None. J. Berry: None. A. Dumont: None. E. Valle-Giler: None.

\section{E-005 TRANSRADIAL ACCESS IN THE PEDIATRIC POPULATION}

N Majmundar*, P Patel, V Dodson, I Bach, J Liu, L Tomycz, P Khandelwal. Rutgers New Jersey Medical School, Newark, NJ

\subsection{6/neurintsurg-2019-SNIS.80}

Introduction/Purpose The transradial approach (TRA) for neurointerventional procedures has recently garnered interest as an alternative to the traditional transfemoral approach (TFA) in adult patients. While the benefits of the TRA have been well reported in adult patients, there is a paucity of reports in the literature regarding its use in the pediatric and adolescent populations. The paucity of literature regarding the TRA for neurointerventional procedures in the pediatric population is likely due to fear of spasm in the narrow caliber radial artery as well as the perceived difficulty in navigating the cerebrovasculature through the TRA. At our institution we have implemented the radial first approach in most adult diagnostic and interventional cases. More recently, we have transitioned to the use of the TRA in pediatric patients as well. Here we present the first reported case series utilizing the TRA in the pediatric population, demonstrating its safety and efficacy for both diagnostic and neurointerventional procedures.

Materials and methods N/A

Results We retrospectively collected data on patients undergoing transradial intervention from July 2018 to Feb 2019. We have 4 pediatric patients in whom the TRA was used. Indications included JNA embolization (2), right ICA pseudoaneurysm which failed medical management (1), and right cerebellar AVM (1). In all cases, a $6 \mathrm{~F}$ sheath with a $6 \mathrm{~F}$ ENVOY guide catheter (Codman- DePuy Synthes, Raynam, MA) was used. One patient developed radial artery vasospasm, and 5 mg verapamil was administered intraarterially post-procedure. The patient did not have any complaints post-procedurally. All preprocedural objectives were met, and none of the interventions required changing to the TFA. The radial artery remained patent in all 4 patients post-procedurally.

Conclusion The TRA is safe, effective, and well tolerated in the pediatric population. Most importantly, the risk of bleeding and arterial damage, the most common complications following interventional procedures, is essentially eliminated with the TRA. Ultrasound guided measurement of the artery to ensure caliber over $2 \mathrm{~mm}$ is recommended in this population to avoid complications.

\begin{tabular}{|c|c|c|c|c|c|}
\hline & Age & Sex & Indication & Catheters Used & Complications \\
\hline Case 1 & 14 & Male & JNA & $\begin{array}{l}\text { 6F system with ENVOY } \\
\text { guide, Simmons } 2\end{array}$ & None \\
\hline Case 2 & 14 & Male & $\begin{array}{l}\text { Right cerebellar } \\
\text { AVM }\end{array}$ & $\begin{array}{l}\text { 6F system with ENVOY } \\
\text { guide, Simmons } 2\end{array}$ & None \\
\hline Case 3 & 15 & Female & $\begin{array}{l}\text { Right ICA } \\
\text { pseudoaneurysm }\end{array}$ & $\begin{array}{l}\text { 6F system with ENVOY } \\
\text { guide, Simmons } 2\end{array}$ & $\begin{array}{l}\text { Right artery } \\
\text { vasospasm, } \\
\text { resolved with } 5 \\
\text { mg intraarterial } \\
\text { verapamil }\end{array}$ \\
\hline Case 4 & 13 & Male & JNA & $\begin{array}{l}\text { 6F system with ENVOY } \\
\text { guide, Simmons } 2\end{array}$ & None \\
\hline
\end{tabular}

Disclosures N. Majmundar: None. P. Patel: None. V. Dodson: None. I. Bach: None. J. Liu: None. L. Tomycz: None. P. Khandelwal: None.

\section{E-006 MULTIPLE FLOW-RELATED INTRACRANIAL ANEURYSMS IN THE SETTING OF CONTRALATERAL CAROTID OCCLUSION: A CASE REPORT AND REVIEW OF THE LITERATURE}

M Mathkour, E McCormack, C Werner, P Amenta. Neurosurgery, Tulane Medical Center, NEW ORLEANS, LA

10.1136/neurintsurg-2019-SNIS.81

Background Severe stenosis or occlusion of one internal carotid artery (ICA) may result in increased demand and altered 